\title{
Improved LFIAs for highly sensitive detection of BNP at point-of-care
}

\author{
This article was published in the following Dove Press journal: \\ International Journal of Nanomedicine \\ 15 June 2017 \\ Number of times this article has been viewed
}

\author{
Yan Gong ${ }^{1-3}$ \\ Jie $\mathrm{Hu}^{1,2}$ \\ Jane Ru Choi ${ }^{2}$ \\ Minli You',2 \\ Yamin Zheng ${ }^{1,2}$ \\ Bo $\mathrm{Xu}^{4}$ \\ Ting Wen ${ }^{3}$ \\ Feng $\mathrm{Xu}^{1,2}$ \\ 'The Key Laboratory of Biomedical \\ Information Engineering of Ministry of \\ Education, Department of Biomedical \\ Engineering, School of Life Science \\ and Technology, Xi'an Jiaotong \\ University, ${ }^{2}$ Bioinspired Engineering \\ and Biomechanics Center (BEBC), \\ Xi'an Jiaotong University, ${ }^{3}$ Xi'an \\ Diandi Biotech Company, ${ }^{4}$ School of \\ Finance and Economics, Xi'an Jiaotong \\ University, Xi'an, People's Republic \\ of China
}

\begin{abstract}
Heart failure (HF) has become a major cause of morbidity and mortality with a significant global economic burden. Although well-established clinical tests could provide early diagnosis, access to these tests is limited in developing countries, where a relatively higher incidence of HF is present. This has prompted an urgent need for developing a cost-effective, rapid and robust diagnostic tool for point-of-care (POC) detection of HF. Lateral flow immunoassay (LFIA) has found widespread applications in POC diagnostics. However, the low sensitivity of LFIA limits its ability to detect important HF biomarkers (e.g., brain natriuretic peptide [BNP]) that are normally present in low concentration in blood. To address this issue, we developed an improved LFIA by optimizing the gold nanoparticle (GNP)-antibody conjugate conditions (e.g., the conjugate $\mathrm{pH}$ and the amount of added antibody), the diameter of GNP and the concentration of antibody embedded on the test line and modifying the structure of test strip. Through these improvements, the proposed test strip enabled the detection of BNP down to $0.1 \mathrm{ng} / \mathrm{mL}$ within 10-15 min, presenting $\sim 15$-fold sensitivity enhancement over conventional lateral flow assay. We also successfully applied our LFIA in the analysis of BNP in human serum samples, highlighting its potential use for clinical assessment of HF. The developed LFIA for BNP could rapidly rule out HF with the naked eye, offering tremendous potential for POC test and personalized medicine.

Keywords: heart failure, biomarker, colorimetric assays, personalized medicine
\end{abstract}

\section{Introduction}

Heart failure (HF) is prevalent all over the world, which has become a major cause of mortality and morbidity. ${ }^{1-3}$ According to a report from the American Heart Association, there were $\sim 5.1$ million people diagnosed with HF annually in the United States, of which $\sim 50 \%$ of them die within 5 years of diagnosis. ${ }^{4}$ The prevalence is predicted to increase by $25 \%$ in $2030,5,6$ and the financial burden is estimated to rise from $\$ 32$ billion in 2013 to $\$ 70$ billion in $2030 .^{7}$ Generally, HF is classified into four stages based on the progression of the disease, where effective interventions can be taken at early stages to prevent or attenuate its progression. ${ }^{8}$ Therefore, early diagnosis of HF is of paramount importance. The existing clinical diagnosis of HF is mainly based on the electrocardiogram (ECG), electrocardiography, imaging tests (e.g., chest X-ray) and laboratory tests (blood and urine tests), which are equipment dependent, timeconsuming and expensive. Thus, they are less applicable in resource-limited settings, ${ }^{9}$ especially in developing countries where access to health care is limited while higher incidence of HF is present. Therefore, a more feasible tool for early and rapid diagnosis of HF in resource-limited areas is vital to release the local economic pressure and reduce the threat of this disease.

To address the issue, point-of-care (POC) testing of cardiac biomarkers, which is a promising method for improving disease management, ${ }^{10}$ holds a significant potential. ${ }^{11}$ 
Ideal biomarkers for early diagnosis of HF should be highly specific, sensitive and easily accessible. Various biomarkers have been identified for HF, such as renin, norepinephrine, endothelin-1 and natriuretic peptides. ${ }^{12,13}$ Among these, brain natriuretic peptide (BNP) and the N-terminal fragment of BNP precursor (NT-proBNP) in serum have been known as the gold standard to identify HF and widely utilized in clinical laboratories. ${ }^{14-16}$ BNP and NT-proBNP are the products of proteolytic processing of the precursor proBNP (pre-proBNP). The removal of signal peptide from preproBNP results in proBNP molecule, which is further split into BNP (biologically active molecule) and NT-proBNP (inactive amino terminal fragment). Since small soluble molecules are preferred for early diagnosis due to their fast release kinetics and rapid diffusion from injured tissue to blood, ${ }^{17} \mathrm{BNP}$ is a more desirable cardiac biomarker for detecting HF compared to NT-proBNP ${ }^{14}$ Furthermore, BNP possessing a defined cutoff $(0.1 \mathrm{ng} / \mathrm{mL})^{9}$ is easier to make a judgment than NT-proBNP, whose cutoff is susceptible to patient's age. Therefore, BNP represents a vital blood cardiac biomarker in patients with acute myocardial infarction and advanced HF. ${ }^{12}$

With advances in POC testing, ${ }^{18-22}$ lateral flow assays (LFAs) hold tremendous potential to address the abovementioned challenges ${ }^{23,24}$ due to the simple, affordable and user-friendly features. ${ }^{25}$ However, the existing LFAs are associated with the limitation of poor sensitivity. ${ }^{11,26}$ Several methods have been developed to enhance the sensitivity of LFAs, such as sample concentration, ${ }^{27-30}$ thermal contrast, ${ }^{31}$ fluidic control, ${ }^{32-34}$ temperature-humidity technique, ${ }^{35}$ probe-based signal enhancement, ${ }^{23,36}$ enzyme-based signal amplification ${ }^{37,38}$ and electrochemical devices-based enhancement. ${ }^{39}$ However, these approaches require either external equipment, ${ }^{35}$ high-cost reagents ${ }^{23,37}$ or complicated fabrication with multistep procedure, ${ }^{32}$ limiting their application for POC testing. To date, a low-cost, convenient and equipment-free sensitivity enhancement method has not yet been explored. Hence, there is still an unmet need to develop a simple and sensitive lateral flow immunoassay (LFIA) for the detection of BNP.

In this study, we introduced a highly sensitive and specific LFIA for POC detection of HF through improving the gold nanoparticle (GNP)-antibody conjugate conditions (e.g., the conjugate $\mathrm{pH}$ and the amount of added antibody), optimizing the diameter of GNP and the concentration of capture antibody at the test line, and modifying the structure of lateral flow test strip. Through these improvements, we achieved highly sensitive detection of BNP down to $0.1 \mathrm{ng} / \mathrm{mL}$ within 10-15 min with a $\sim 15$-fold increase in the sensitivity over conventional LFA, ${ }^{30,35,40}$ as further quantified by using a smartphone. We also successfully applied our LFIA in the analysis of BNP in human serum samples to diagnose HF, demonstrating the potential of the proposed simple sensitivity enhancement strategy for clinical assessment. The prototype would enable rapid, cost-effective and highly sensitive BNP detection, offering great potential for POC and personalized diagnostics especially in the developing world.

\section{Materials and methods Reagents and instruments}

Two kinds of anti-BNP antibodies, 24C5 and 50E1, (Abcam, Cambridge, UK) were used as the capture and conjugate antibodies, respectively. The standard BNP antigen was also obtained from Abcam. Goat anti-mouse IgG polyclonal antibody was obtained from Fapon Biotech Inc. (Shenzhen, China). $\mathrm{HAuCl}_{4} \cdot 4 \mathrm{H}_{2} \mathrm{O}$ was supplied by Sinopharm Chemical Reagent Co., Ltd. (Shanghai, China). Trisodium citrate was purchased from Amresco, LLC (Solon, OH, USA). Bovine serum albumin (BSA), trehalose, casein and phosphatebuffered saline (PBS; pH7.4, 0.01 M) were obtained from MP Biomaterials, LLC (Solon, OH, USA). Sucrose was obtained from Aladdin Reagent Co., Ltd. (Shanghai, China). All the components for fabricating lateral flow test paper, including a polyvinyl chloride (PVC) backing pad, conjugate pad, absorbent pad, sample pad and nitrocellulose (NC) membrane (HFB13502S25; EMD Millipore, Billerica, MA, USA), were obtained from Jiening Biotech Co., Ltd. (Shanghai, China). All chemicals employed in this study were analytical reagent grade. Other solutions were prepared with ultrapure water (>18 M $\Omega$ ) from the Barnstead Nanopure ultrapure water purification system (Thermo Fisher Scientific, Waltham, MA, USA).

\section{Preparation of GNPs}

GNPs with average diameter of $13 \pm 3$ and $35 \pm 3 \mathrm{~nm}$ were prepared according to the previously reported protocol. ${ }^{41,42}$ Briefly, 4.5 or $1 \mathrm{~mL}$ of $1 \%$ trisodium citrate and $1 \mathrm{~mL}$ of $1 \%$ chloroauric acid $\left(\mathrm{HAuCl}_{4}\right)$ were successively added to three-neck round-bottom flask filled with $100 \mathrm{~mL}$ boiled ultrapure water. Then, the color of the solution immediately turned from yellow to purple and finally remained wine red. The prepared GNPs ${ }^{43}$ were characterized by using transmission electron microscopy (TEM; JEM-2100F) and ultraviolet-visible (UV/vis) spectrophotometry (Figure S1).

\section{Modification of GNPs}

To make a better combination of GNPs and conjugating antibody, we optimized the $\mathrm{pH}$ of GNP-antibody conjugation 
and the amount of the added antibody. Briefly, certain volumes of potassium carbonate $(0,2,4,6,8$ and $10 \mu \mathrm{L})$ were separately added into the as-prepared $1 \mathrm{~mL}$ GNP solution to adjust the $\mathrm{pH}$ value; then, the excess antibody was added into the abovementioned solution for $10 \mathrm{~min}$ incubation at room temperature (RT). The sodium chloride was subsequently added into each solution, and the optimum $\mathrm{pH}$ was determined based on the color change and absorbance value of each solution (Figure S2A). Similarly, different volumes of conjugating antibody $(0,1,2,3,4$ and $5 \mu \mathrm{L})$ were added into the GNP solution with the optimum $\mathrm{pH}$ to optimize their volume based on the color change and absorbance value of each solution (Figure S2B). Then, 10\% BSA was added to the abovementioned solution and incubated for $10 \mathrm{~min}$ to block nonspecific sites to obtain a final concentration of $0.1 \%$. The supernatant solution was removed after the centrifugation at $12,000 \times g$ for $10 \mathrm{~min}$, and the red pellets were suspended in $0.22 \mathrm{~mL}$ eluent buffer including 1\% BSA, 0.85\% Tris, 5\% trehalose and $20 \%$ sucrose.

\section{Fabrication of lateral flow test strips}

Control and capture antibodies of BNP were diluted with coating buffer ( $2 \%$ trehalose in $0.01 \mathrm{M} \mathrm{PBS})$ to a certain concentration, which were then dispensed on NC membrane as control line and test line and incubated at $37^{\circ} \mathrm{C}$ for $2 \mathrm{~h}$ to immobilize the antibodies. The GNP-Ab conjugates were dispensed on the conjugate pad, and the sample pad was soaked in the treating fluid for half an hour and dried in oven for $2 \mathrm{~h}$. Then, these elements were consecutively mounted on a PVC adhesive backing pad with $2 \mathrm{~mm}$ overlap between each two adjacent pads (Figure 1A). The as-assembled pads were cut into strips $(2.5 \mathrm{~mm}$ ) by Rapid Test Cutter ZQ2000 (Shanghai Kinbio Tech Co., Ltd, Shanghai, China).

\section{BNP detection using LFIAs}

A typical LFIA was performed as follows: the sample solution was dispensed onto the sample pad by using a pipette. The color changes at both test and control lines were observed after $10 \mathrm{~min}$. For quantitative analysis, images of the test zones were captured with a smartphone (iPhone 6s) and their optical densities were determined using the Image-Pro Plus software.

\section{Clinical analysis}

To prove the sensitivity and specificity of the improved LFIA for BNP detection in clinical serum samples, we tested the LFIA with different concentrations of BNP and four kinds of cardiac biomarkers in spiked human serum. A series of spiked BNP sera (i.e., 1, 0.5, 0.2, 0.1 and $0.01 \mathrm{ng} / \mathrm{mL}$ ) and other cardiac biomarkers sera were prepared by diluting their antigen stock solution with normal human sera, respectively. The spiked concentration of four interfering cardiac biomarkers was 10 times of their clinical cutoff (i.e., $100 \mu \mathrm{g} / \mathrm{mL}$ of C-reactive protein [CRP], $1 \mu \mathrm{g} / \mathrm{mL}$ of myoglobin [Myo], $30 \mathrm{ng} / \mathrm{mL}$ of troponin I [cTnI] and $3 \mathrm{ng} / \mathrm{mL}$ of NT-proBNP). ${ }^{4-47}$ After LFIAs were finished, the results were captured with iPhone $6 \mathrm{~s}$ and the optical densities of test zones were determined using the Image-Pro Plus software for further quantitative analysis.

\section{Statistical analysis}

Student's $t$-test was used to compare the data among different groups in optimization assays. Data were expressed as mean \pm standard error of the mean (SEM) of three independent experiments $(\mathrm{n}=3) . P<0.05$ was reported as statistically significant.

\section{Results and discussion The work principle of LFIA}

The principle of the improved LFIA is based on an on-strip sandwich $\mathrm{Ag}-\mathrm{Ab}$ reaction, and the protocol is illustrated in Figure $1 \mathrm{~B}$. In the presence of target $\mathrm{BNP}$, the target would bind to the GNP-Ab, forming GNP-Ab target complexes, which would in turn interact with the immobilized $\mathrm{Ab}$ at the test line to produce a red signal detectable by the naked eye. The excess GNP-Ab complexes would then bind to the immobilized secondary $\mathrm{Ab}$ at the control line. To achieve rapid POC analysis, qualitative analysis was performed by observing the color changes, whereas quantitative analysis was achieved with a smartphone (iPhone $6 \mathrm{~s}$ ) based on the optical density of the test zone.

\section{Optimization of LFIAs}

Paper material, GNP and detection elements have been shown to have significant effect on the performance of LFA. ${ }^{48,49}$ However, these three elements are the personal choice of the research group for developing high-sensitive $\mathrm{LFA}^{50}$ and have not been optimized simultaneously, although personal choice may satisfy the requirement for detecting some targets. Therefore, we developed an improved LFIA for highly sensitive detection of BNP by simultaneously modifying the structure of test strip and optimizing the GNP-Ab conjugate conditions, the diameter of GNP (Figure 1C) and the concentration of antibody at the detect line (Figure 1D).

In our previous study, ${ }^{23}$ the lateral flow test strip was constituted with NC membrane, absorbent pad and sample pad (Figure 2A[i]). However, throughout our experiment on BNP detection, we found that the complex of GNP-Ab 


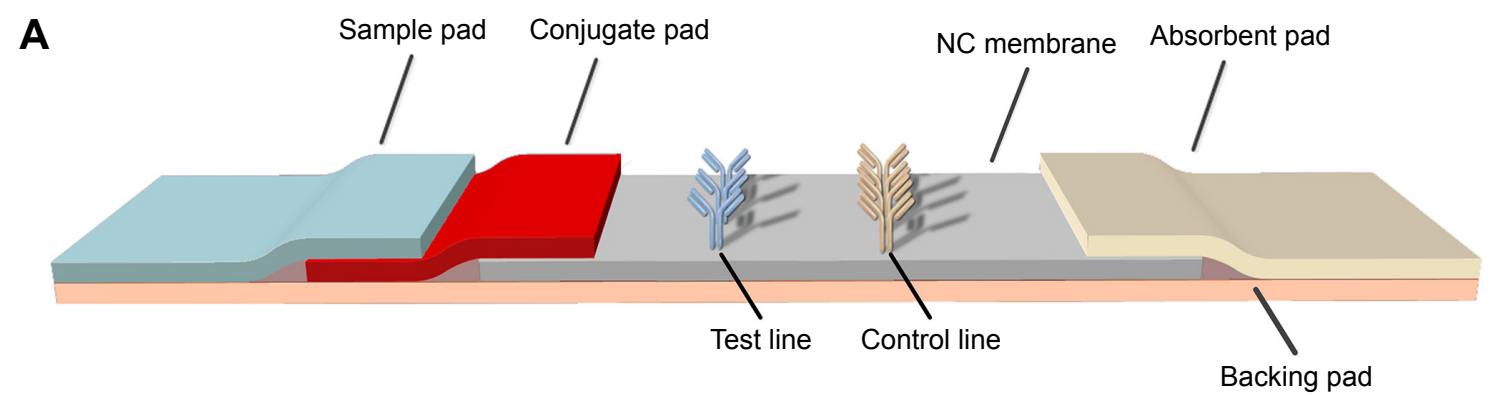

B
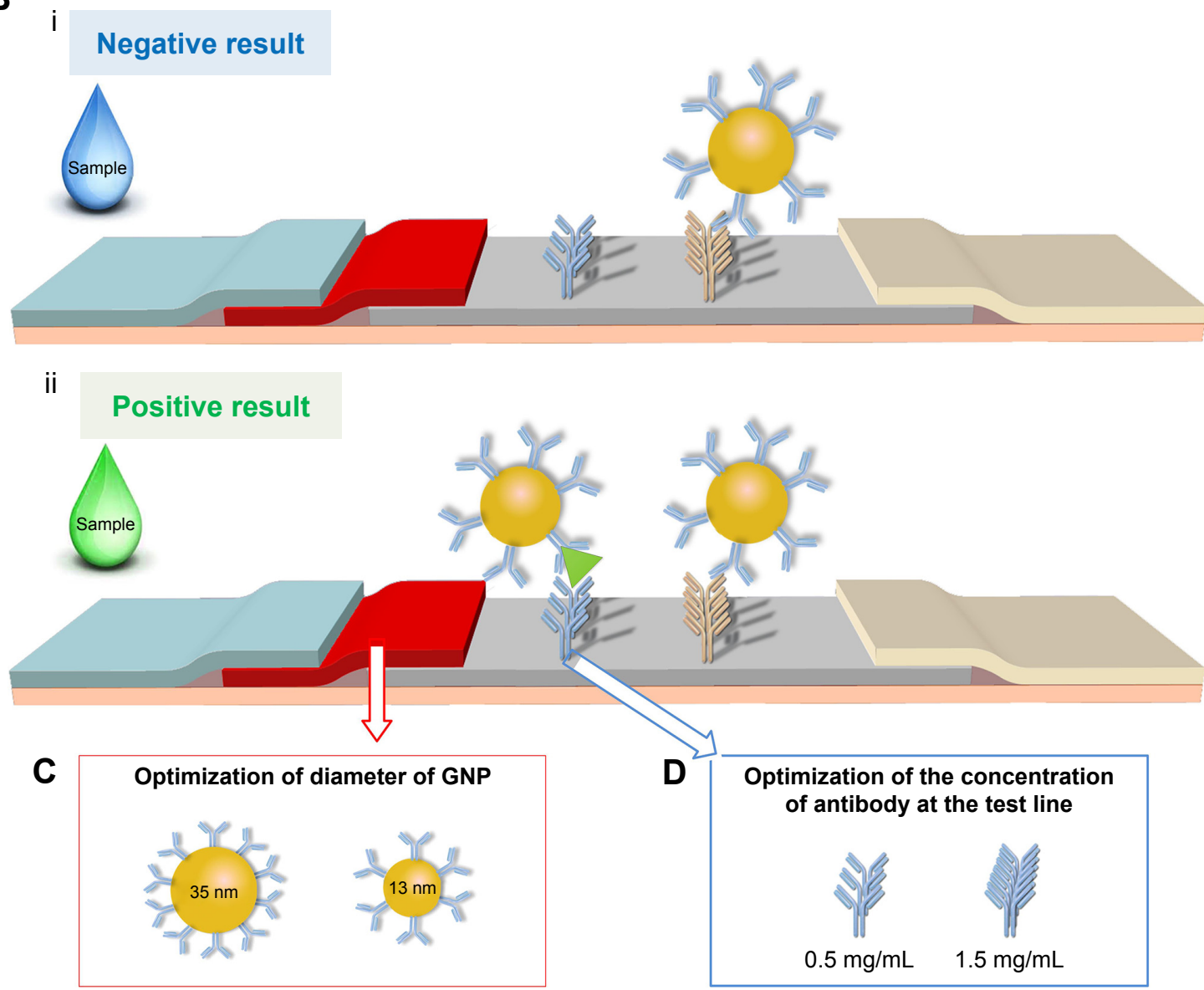

Figure I The schematic of the optimized LFIA for BNP detection.

Notes: (A) The structure of previous LFA is adjusted by adding a conjugate pad to form a new type of LFIA. (B) The negative result (i) and positive result (ii) show the principle of the LFIA. (C) The diameter of GNP is adjusted from I $3 \pm 3$ to $35 \pm 3 \mathrm{~nm}$. (D) The concentration of test line is adjusted from 0.5 to $1.5 \mathrm{mg} / \mathrm{mL}$.

Abbreviations: GNP, gold nanoparticle; BNP, brain natriuretic peptide; LFA, lateral flow assay; LFIA, lateral flow immunoassay; NC, nitrocellulose.

was unable to completely wick through the previously used sample pad, resulting in the waste and reduction of the effective tracer and degrade the detection sensitivity. This is because different paper materials are applied for different elements of LFIAs, ${ }^{50-52}$ where the inert glass fiber is used as the sample pad, which may not be suitable for the release of GNP-Ab. Therefore, in our modified test strip (Figure 2A[ii]), we introduced an extra surface-modified polyester layer as the conjugate pad (Figure $2 \mathrm{~B}[\mathrm{i}]$ ), which is much thinner than the sample pad to get a complete release of GNP-Ab. Besides, we also adjusted the composition of eluent buffer, where the trehalose was added to protect the activity of conjugate $\mathrm{Ab}^{53}$ and the BSA was added to block the nonspecific binding between the GNP-Ab and NC membrane to eliminate the background signal. With the introduction of the conjugate pad and the change of composition of eluent buffer, the GNP-Ab conjugation was completely released, the background color was eliminated 


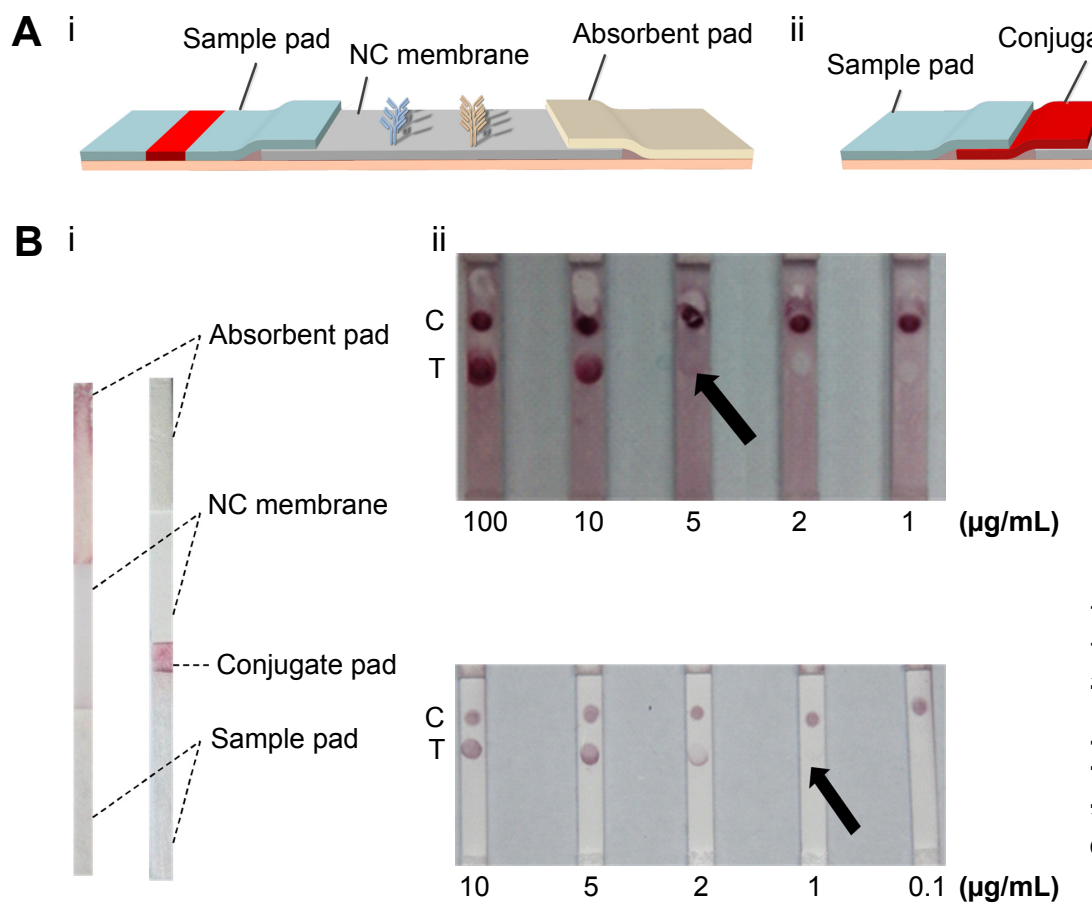

Figure 2 The effect of improved structure of test strip on LFIA performance.

Notes: (A) The schematic diagrams show the structure of test strip before (i) and after (ii) incorporating a piece of conjugate pad into the test strip. (B) The images (i) of comparison of conventional and improved LFAs and the results (ii) which show that the detection limit is improved from $5 \mu \mathrm{g} / \mathrm{mL}$ to I $\mu \mathrm{g} / \mathrm{mL}$ (the arrows reference the detection limit of the results).

Abbreviations: LFA, lateral flow assay; LFIA, lateral flow immunoassay; NC, nitrocellulose; C, control line; T, test line.

and the signal-noise ratio and sensitivity of detection results were enhanced (Figure 2B[ii]).

Since the principle of LFIA was based on the interaction of the antibody and GNP through hydrophobic and ionic bonds, the condition of the conjugation of antibody with GNP was one of the most important parameters for this immunoassay ${ }^{54}$ To optimize the condition of the conjugation, we adjusted the $\mathrm{pH}$ value of GNP solution and the amount of conjugating antibody and found that the best condition of $\mathrm{pH}$ value was 8 and the amount of conjugating antibody was $\sim 20 \mu$ g (i.e., $6.8 \mathrm{mg} / \mathrm{mL}$ ). Accordingly, $4 \mu \mathrm{L}$ of $0.2 \mathrm{M}$ potassium carbonate (to make sure the $\mathrm{pH}$ value is 8 ) and $3 \mu \mathrm{L}$ conjugating antibody (Figure S2) were successively added into the as-prepared $1 \mathrm{~mL}$ GNP solution for $10 \mathrm{~min}$ incubation at RT. The resulting GNP solution was used in the following experiments. Besides, we also adjusted the concentration of the immobilized $\mathrm{Ab}$ at the test line in the range of $0.5-1.5 \mathrm{mg} / \mathrm{mL}$ (Figure 3). The results indicate that the coating antibody concentration of $1.5 \mathrm{mg} / \mathrm{mL}$ showed greater signal of LFIA in BNP detection relative to $0.5 \mathrm{mg} / \mathrm{mL}(\mathrm{n}=3, P<0.05)$. In fact, the LFIA with $0.5 \mathrm{mg} / \mathrm{mL}$ antibody can achieve a detection limit of $5 \mathrm{ng} / \mathrm{mL}$
( $\mathrm{n}=3, P<0.05$ ), and with $1.5 \mathrm{mg} / \mathrm{mL}$ antibody can achieve a detection limit of $2 \mathrm{ng} / \mathrm{mL}$ ( $\mathrm{n}=3, P<0.05)$, representing 2.5 -fold signal enhancement. The sensitivity enhanced with the increasing concentration of test line. But concomitantly, high concentration of $\mathrm{Ab}$ at test line $(>1.5 \mathrm{mg} / \mathrm{mL})$ resulted in an observed false-positive result. Therefore, $1.5 \mathrm{mg} / \mathrm{mL}$ was selected as the optimized concentration.

Since the diameter of GNP would affect the optical density of test line detected by the naked eye, we investigated the effect of different diameter of GNP $(13 \pm 3$ and $35 \pm 3 \mathrm{~nm})$ on LFIA (Figure 4). We found that the LFIA with $35 \pm 3 \mathrm{~nm}$ GNP showed greater signal in BNP detection compared to that with $13 \pm 3 \mathrm{~nm}$ GNP $(\mathrm{n}=3, P<0.05)$. Indeed, the LFIA with $13 \pm 3 \mathrm{~nm}$ GNP can achieve a detection limit of $5 \mathrm{ng} / \mathrm{mL}$ ( $\mathrm{n}=3, P<0.05)$, and LFIA with $35 \pm 3 \mathrm{~nm}$ GNP can achieve a detection limit of $1 \mathrm{ng} / \mathrm{mL}(\mathrm{n}=3, P<0.05)$, representing fivefold signal enhancement. According to the literature, ${ }^{49,55,56}$ the particles reported (i.e., GNP) can be more easily seen when the size of the particles is larger, but the stability of the colloid will decrease when the diameter is $>40 \mathrm{~nm},{ }^{56}$ which may result in the steric hindrance and hamper the antigenantibody interaction. ${ }^{50}$ Thus, we used the diameter of $13 \pm 3$ 

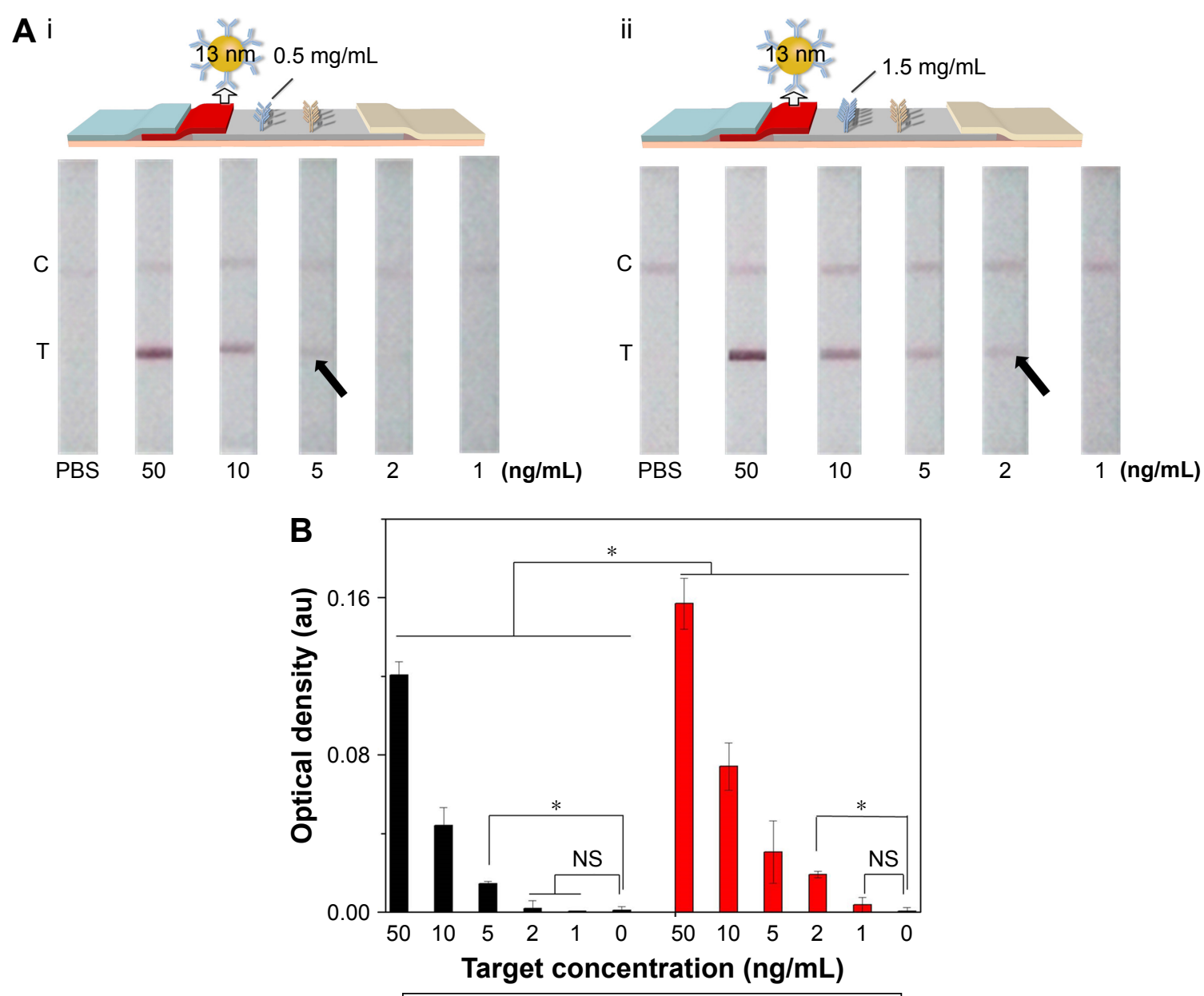

$13 \mathrm{~nm}, 0.5 \mathrm{mg} / \mathrm{mL} \square 13 \mathrm{~nm}, 1.5 \mathrm{mg} / \mathrm{mL}$

Figure 3 The effect of antibody concentration at the test line on LFIA performance.

Notes: (A) The schematic diagram and results of the LFIA with $0.5 \mathrm{mg} / \mathrm{mL}$ (i) and $1.5 \mathrm{mg} / \mathrm{mL}$ coating antibody (ii). (B) Optical density analysis of (A) ( $\mathrm{n}=3$, $* P<0.05)$. (The arrows reference the detection limit of the results).

Abbreviations: LFIA, lateral flow immunoassay; NS, no significance; PBS, phosphate-buffered saline; C, control line; T, test line.

and $35 \pm 3 \mathrm{~nm}$ in this study, and the result showed that the optimum diameter is $35 \pm 3 \mathrm{~nm}$.

\section{Application of the improved LFIA}

First, we used different BNP concentrations to evaluate the performance of optimized LFIAs. With the optimum concentration of antibodies $(1.5 \mathrm{mg} / \mathrm{mL})$, GNP diameter $(35 \mathrm{~nm})$ and improved structure of test strip (with conjugate pad), the proposed test strip could sensitively detect BNP at $0.1 \mathrm{ng} / \mathrm{mL}(\mathrm{n}=3, P<0.05)$ with $\sim 15$-fold signal enhancement over unmodified LFIA (Figure 5), which represents the clinical threshold to rule out HF. Moreover, we also assessed the limit of detection of the method. According to the concentration that shows three times of noise detection (signal to noise ratio $=0.0955), 57,58$ the estimated detection limit of our method is $95.5 \mathrm{pg} / \mathrm{mL}$.

Subsequently, to further show the potential of our proposed LFIA for HF diagnosis at the POC, we tested the improved strip with clinical serum samples. Briefly, we spiked different concentrations of standard BNP antigen (i.e., 1, 0.5, 0.2, 0.1, 0.01 and $0 \mathrm{ng} / \mathrm{mL}$ ) and four kinds of interfering cardiac biomarkers with 10 -fold concentration of their clinical cutoff in normal human serum and then detected them using the proposed test strips. We found that the improved LFIA can detect BNP as low as $0.1 \mathrm{ng} / \mathrm{mL}$ $(\mathrm{n}=3, P<0.05)$ in spiked serum, which reaches the clinical threshold (Figure 6A). Comparing to the negative detection results of four interfering biomarkers, the test strip showed positive in BNP detection, indicating the improved LFIA with a good specificity (Figure 6B).

Besides, with the existing target concentration $(0.01,0.1$, $0.2,0.5$ and $1 \mathrm{ng} / \mathrm{mL}$ ) and their corresponding optical densities, we obtained a calibration curve $(y=0.00398+0.08082 x)$ with $R^{2}=0.99881$, showing an excellent linear relationship between target concentration and optical density (Figure 7). Therefore, when the proposed LFIA detected the BNP sera 
A i

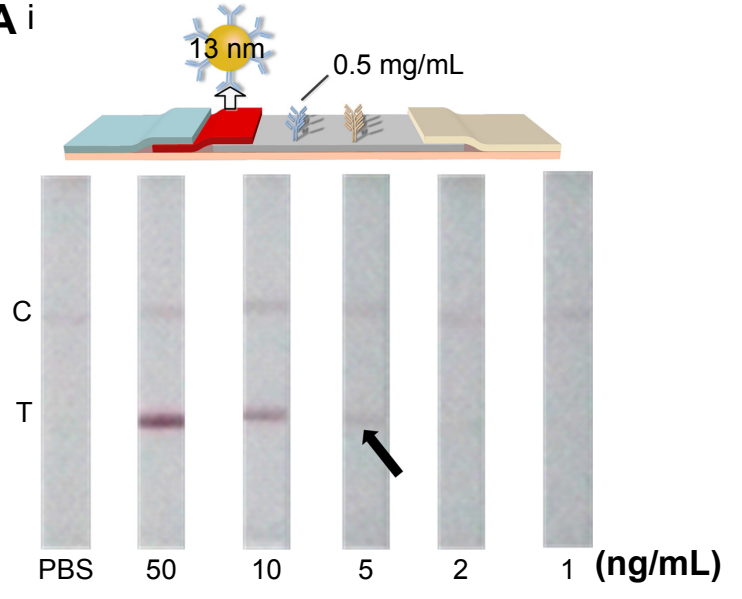

ii

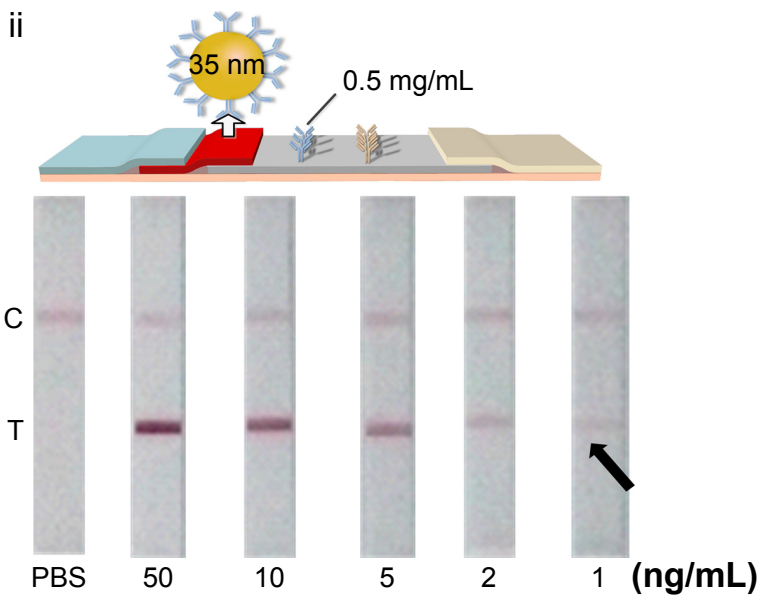

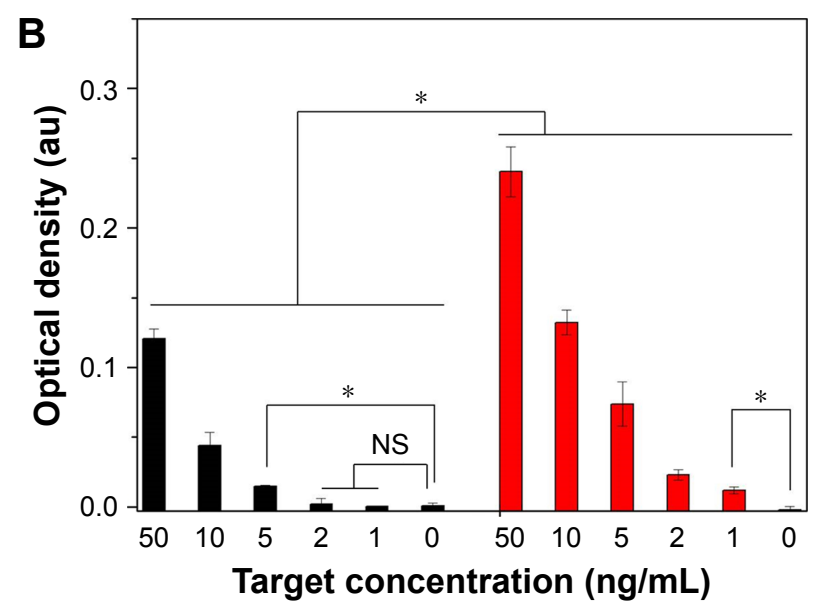

$13 \mathrm{~nm}, 0.5 \mathrm{mg} / \mathrm{mL} \square 35 \mathrm{~nm}, 0.5 \mathrm{mg} / \mathrm{mL}$

Figure 4 The effect of GNP diameter on LFIA performance.

Notes: (A) The schematic diagram and results of the LFIA with I $3 \pm 3 \mathrm{~nm}$ GNP (i) and $35 \pm 3 \mathrm{~nm}$ GNP (ii). (B) Optical density analysis of $(\mathbf{A})$ ( $\mathrm{n}=3$, $* P<0.05)$. (The arrows reference the detection limit of the results).

Abbreviations: GNP, gold nanoparticle; LFIA, lateral flow immunoassay; NS, no significance; PBS, phosphate-buffered saline; C, control line; T, test line.

A

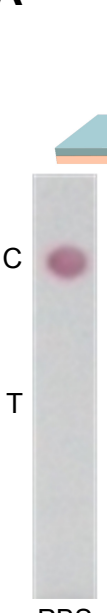

PBS $\frac{-174}{35} \mathrm{~nm}$

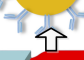

$1.5 \mathrm{mg} / \mathrm{mL}$
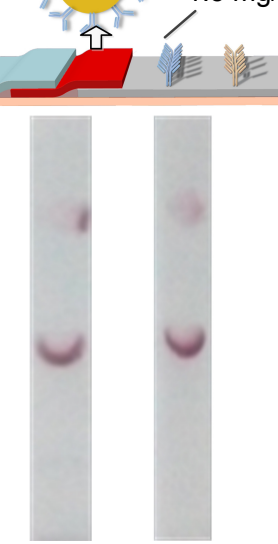

1

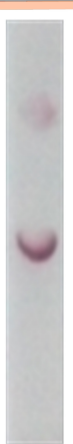

0.5

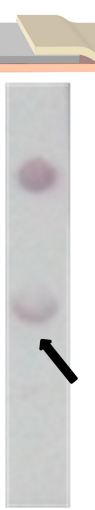

0.1
B

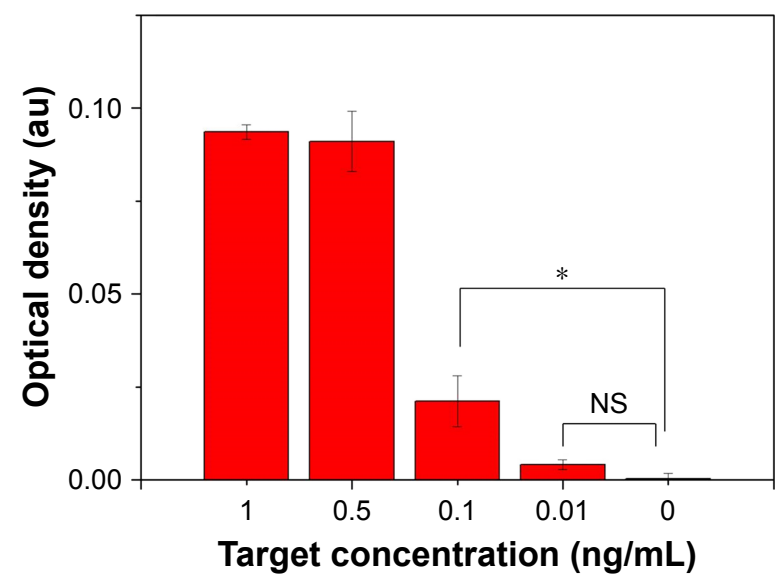

Figure 5 Sensitivity assay using the optimized LFIA.

Notes: (A) The images showing LFIA results in the detection of different concentrations of BNP solutions. (B) Optical density analysis of $(\mathbf{A})$ ( $n=3$, $* P<0.05)$. (The arrow references the detection limit of the results).

Abbreviations: BNP, brain natriuretic peptide; LFIA, lateral flow immunoassay; NS, no significance; PBS, phosphate-buffered saline; C, control line; T, test line. 

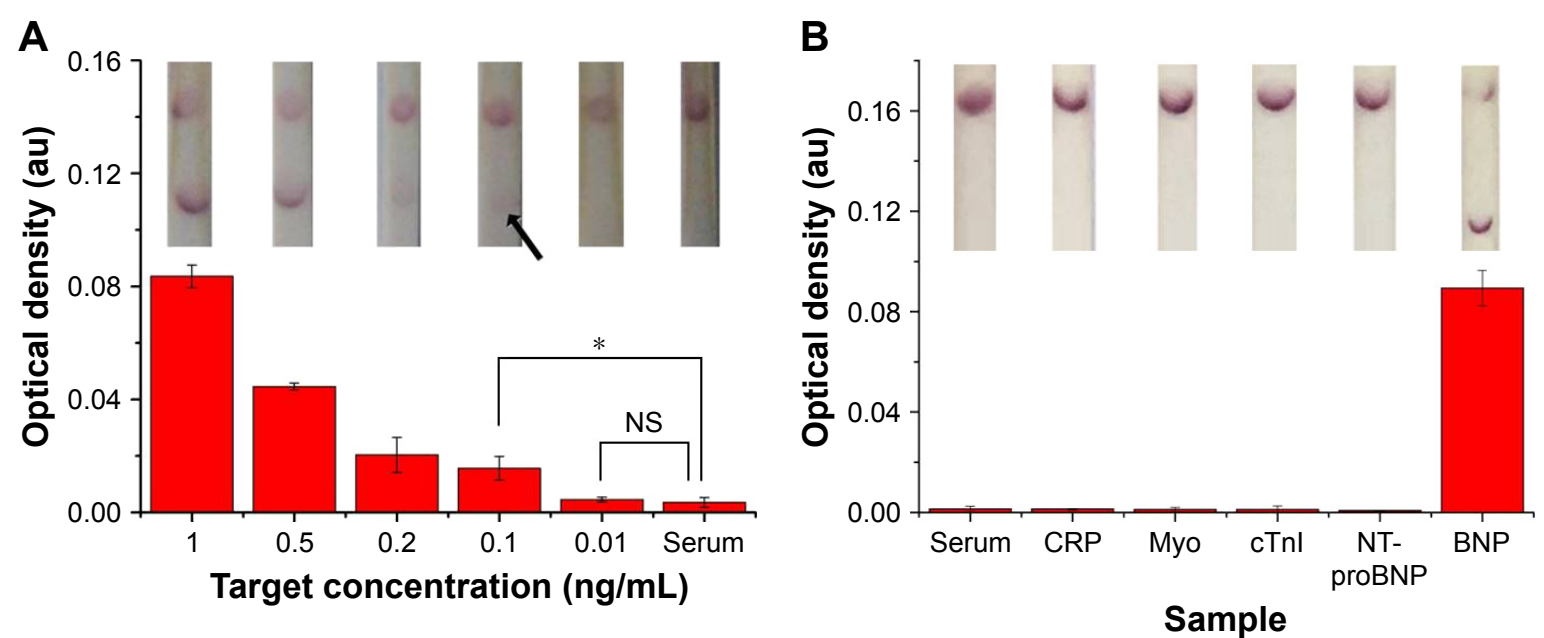

Figure 6 Clinical sample testing using the optimized LFIA.

Notes: (A) The sensitivity results of optimized LFIA detect BNP in human sera (the inset shows the images of LFA results in the detection of different concentrations of BNP solutions). (B) The specificity results of optimized LFIA detect BNP in human sera $(n=3, * P<0.05)$ (the inset shows the images of LFA results in the detection of different samples). (The arrow references the detection limit of the results).

Abbreviations: BNP, brain natriuretic peptide; CRP, C-reactive protein; cTnl, troponin I; LFIA, lateral flow immunoassay; Myo, myoglobin; NS, no significance; NT-proBNP, $\mathrm{N}$-terminal fragment of BNP precursor.

with $0.4,0.6$ and $0.8 \mathrm{ng} / \mathrm{mL}$, their optical densities were determined using the Image-Pro Plus software. Then, we used the calibration curve to separately convert the optical density to calculate the concentration, and the recovery rates are demonstrated in Table 1 , with $0.8 \mathrm{ng} / \mathrm{mL}$ associated with the largest recovery rates $(0.976 \pm 0.006)$.

In fact, various methods have been developed for the diagnosis of BNP, such as enzyme-linked immunosorbent assay (ELISA) and chemiluminescent immunoassay (CLIA). ${ }^{59-61}$ Although these methods have achieved quantitative detection with high sensitivity $(2-10 \mathrm{pg} / \mathrm{mL}){ }^{60}$ they are either timeconsuming $(\sim 12-36 \mathrm{~h})$, complicated (need tedious procedures), inconvenient (require cumbersome instruments and professional operators) or need large blood volume $(\sim 5 \mathrm{~mL})$,

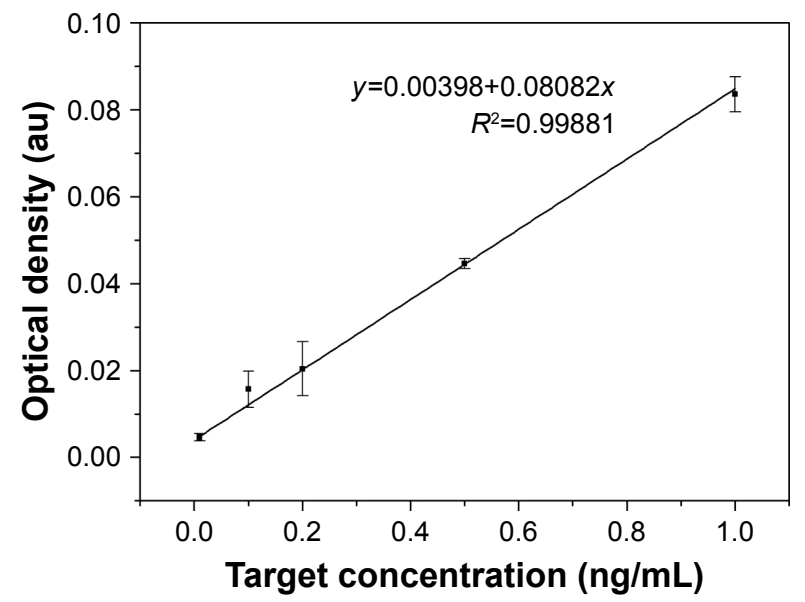

Figure 7 The calibration curve of relationship between target concentration and optical density. which significantly limit their accessibility in resourcelimited settings. ${ }^{61}$ Our proposed test strip is simple, low cost and equipment free, which can be performed by untrained users in resource-limited settings in 10-15 min using only a drop of blood, eliminating the need for large and expensive equipment or laboratory infrastructure. More importantly, compared with the existing methods, our improved LFIA can also meet the clinical demand. It has a clinically relevant BNP level detection limit of $0.1 \mathrm{ng} / \mathrm{mL}$, which is the cutoff point to rule out the HF, ${ }^{9}$ making it highly suitable for early and rapid diagnosis of $\mathrm{HF}$ at the POC.

\section{Conclusion}

We developed a simple, cost-effective and highly sensitive LFIA for rapid BNP detection at the POC. We optimized the conjugating condition of GNP-Ab, the diameter of GNP and the concentration of immobilized $\mathrm{Ab}$ at test line and adjusted the structure of conventional LFA. Through these improvements, the proposed LFIA could sensitively detect BNP at $0.1 \mathrm{ng} / \mathrm{mL}$ in serum samples, representing $\sim 15$-fold

Table I The recovery rates of other three concentrations of BNP

\begin{tabular}{lllll}
\hline $\begin{array}{l}\text { Added } \\
\text { concentration } \\
\text { (ng/mL) }\end{array}$ & $\begin{array}{l}\text { Optical } \\
\text { density } \\
(\mathrm{au})\end{array}$ & $\begin{array}{l}\text { Calculated } \\
\text { concentration } \\
(\mathrm{ng} / \mathrm{mL})\end{array}$ & $\begin{array}{l}\text { Standard } \\
\text { deviation }\end{array}$ & $\begin{array}{l}\text { Recovery } \\
\text { rates }\end{array}$ \\
\hline 0.4 & 0.067 & 0.374 & 0.008 & $0.937 \pm 0.020$ \\
0.6 & 0.044 & 0.499 & 0.007 & $0.83 \mathrm{I} \pm 0.012$ \\
0.8 & 0.034 & $0.78 \mathrm{I}$ & 0.005 & $0.976 \pm 0.006$ \\
\hline
\end{tabular}

Abbreviation: BNP, brain natriuretic peptide. 
signal improvement over conventional LFIA. We envision that the proposed test strip may show great potential to rapidly detect $\mathrm{HF}$ and facilitate early and appropriate health management at the POC.

\section{Acknowledgments}

This work was financially supported by the National Instrumentation Program of China (2013YQ190467). All the data generated during this study are included within the published article and its Supplementary materials.

\section{Disclosure}

The authors report no conflicts of interest in this work.

\section{References}

1. Fleischmann KE, Beckman JA, Buller CE, et al. 2009 ACCF/AHA focused update on perioperative beta blockade: a report of the American college of cardiology foundation/American heart association task force on practice guidelines. Circulation. 2009;120(21): 2123-2151.

2. Dickstein K, Cohen-Solal A, Filippatos G, et al. ESC guidelines for the diagnosis and treatment of acute and chronic heart failure 2008: the Task Force for the diagnosis and treatment of acute and chronic heart failure 2008 of the European Society of Cardiology. Developed in collaboration with the Heart Failure Association of the ESC (HFA) and endorsed by the European Society of Intensive Care Medicine (ESICM). Eur J Heart Fail. 2008;10(10):933-989.

3. Wang C-C, Chen J-H, Yu W-C, et al. 2012 Guidelines of the Taiwan Society of Cardiology (TSOC) for the diagnosis and treatment of heart failure. Acta Cardiol Sin. 2012;28:161-195.

4. Go AS, Mozaffarian D, Roger VL, et al. Heart disease and stroke statistics - 2013 update: a report from the American Heart Association. Circulation. 2013;127(1):e6-e245.

5. Roger VL, Weston SA, Redfield MM, et al. Trends in heart failure incidence and survival in a community-based population. JAMA. 2004 292(3):344-350

6. Levy D, Kenchaiah S, Larson MG, et al. Long-term trends in the incidence of and survival with heart failure. $N$ Engl J Med. 2002; 347(347):1397-1402.

7. Heidenreich PA, Trogdon JG, Khavjou OA, et al. Forecasting the future of cardiovascular disease in the United States: a policy statement from the American Heart Association. Circulation. 2011;123(8): 933-944.

8. Hunt SA, Baker DW, Chin MH, et al. ACC/AHA guidelines for the evaluation and management of chronic heart failure in the adult: executive summary. A report of the American College of Cardiology/American Heart Association Task Force on Practice Guidelines (Committee to revise the 1995 Guidelines for the Evaluation and Management of Heart Failure) developed in collaboration with the International Society for Heart and Lung Transplantation endorsed by the Heart Failure Society of America. J Am Coll Cardiol. 2001;38(7):2101-2113.

9. McCullough PA, Nowak RM, McCord J, et al. B-type natriuretic peptide and clinical judgment in emergency diagnosis of heart failure: analysis from breathing not properly (BNP) multinational study. Circulation. 2002;106(4):416-422.

10. Sharma S, Zapatero-Rodríguez J, Estrela P, O’Kennedy R. Point-of-care diagnostics in low resource settings: present status and future role of microfluidics. Biosensors. 2015;5(3):577-601.

11. McBride JD, Cooper MA. A high sensitivity assay for the inflammatory marker C-Reactive protein employing acoustic biosensing. J Nanobiotechnology. 2008;6(1):1.
12. Tsutamoto T, Wada A, Maeda K, et al. Plasma brain natriuretic peptide level as a biochemical marker of morbidity and mortality in patients with asymptomatic or minimally symptomatic left ventricular dysfunction. Comparison with plasma angiotensin II and endothelin-1. Eur Heart J. 1999;20(24):1799-1807.

13. Clerico A, Passino C, Franzini M, Emdin M. Cardiac biomarker testing in the clinical laboratory: where do we stand? General overview of the methodology with special emphasis on natriuretic peptides. Clin Chim Acta. 2015;443:17-24.

14. Seferian KR, Tamm NN, Semenov AG, et al. The brain natriuretic peptide (BNP) precursor is the major immunoreactive form of BNP in patients with heart failure. Clin Chem. 2007;53(5):866-873.

15. Belenky A, Smith A, Zhang B, et al. The effect of class-specific protease inhibitors on the stabilization of B-type natriuretic peptide in human plasma. Clin Chim Acta. 2004;340(1-2):163-172.

16. Emdin $M$, Passino $C$, Prontera $C$, et al. Comparison of brain natriuretic peptide (BNP) and amino-terminal ProBNP for early diagnosis of heart failure. Clin Chem. 2007;53(7):1289-1297.

17. McDonnell B, Hearty S, Leonard P, O'Kennedy R. Cardiac biomarkers and the case for point-of-care testing. Clin Biochem. 2009;42(7-8): $549-561$.

18. Hua X, Qian G, Yang J, et al. Development of an immunochromatographic assay for the rapid detection of chlorpyrifos-methyl in water samples. Biosens Bioelectron. 2010;26(1):189-194.

19. Choi JR, Hu J, Tang R, et al. An integrated paper-based sample-toanswer biosensor for nucleic acid testing at the point of care. Lab Chip. 2016;16(3):611-621.

20. Choi JR, Tang R, Wang S, Abas WABW, Pingguan-Murphy B, Xu F. Paper-based sample-to-answer molecular diagnostic platform for pointof-care diagnostics. Biosens Bioelectron. 2015;74:427-439.

21. Kolosova AY, Sibanda L, Dumoulin F, et al. Lateral-flow colloidal gold-based immunoassay for the rapid detection of deoxynivalenol with two indicator ranges. Anal Chim Acta. 2008;616(2):235-244.

22. Guo Y-R, Liu S-Y, Gui W-J, Zhu G-N. Gold immunochromatographic assay for simultaneous detection of carbofuran and triazophos in water samples. Anal Biochem. 2009;389(1):32-39.

23. Hu J, Wang L, Li F, et al. Oligonucleotide-linked gold nanoparticle aggregates for enhanced sensitivity in lateral flow assays. Lab Chip. 2013;13(22):4352-4357.

24. Choi JR, Hu J, Wang S, et al. Paper-based point-of-care testing for diagnosis of dengue infections. Crit Rev Biotechnol. 2017;37(1): 100-111.

25. Choi JR, Hu J, Gong Y, et al. An integrated lateral flow assay for effective DNA amplification and detection at the point of care. Analyst. 2016;141(10):2930-2939.

26. Maisel AS, Krishnawswamy P, Nowak RM. Rapid measurement of B-type natriuretic peptide in the emergency diagnosis of heart failure. N Engl J Med. 2002;347(3):161-167.

27. Moghadam BY, Connelly KT, Posner JD. Two orders of magnitude improvement in detection limit of lateral flow assays using isotachophoresis. Anal Chem. 2015;87(2):1009-1017.

28. Chiu RY, Jue E, Yip AT, et al. Simultaneous concentration and detection of biomarkers on paper. Lab Chip. 2014;14(16):3021-3028.

29. Tang RH, Yang H, Choi JR, et al. Advances in paper-based sample pretreatment for point-of-care testing. Crit Rev Biotechnol. 2017;37(4): 411-428.

30. Tang R, Yang H, Choi JR, et al. Improved sensitivity of lateral flow assay using paper-based sample concentration technique. Talanta. 2016; 152:269-276.

31. Qin Z, Chan WC, Boulware DR, Akkin T, Butler EK, Bischof JC. Significantly improved analytical sensitivity of lateral flow immunoassays by using thermal contrast. Angew Chem Int Ed Engl. 2012;124(18): 4434- 4437.

32. Rivas L, Medina-Sánchez M, de la Escosura-Muñiz A, Merkoçi A. Improving sensitivity of gold nanoparticle-based lateral flow assays by using wax-printed pillars as delay barriers of microfluidics. Lab Chip. 2014;14(22):4406-4414. 
33. Choi JR, Liu Z, Hu J, et al. Polydimethylsiloxane-paper hybrid lateral flow assay for highly sensitive point-of-care nucleic acid testing. Anal Chem. 2016;88(12):6254-6264.

34. Choi JR, Yong KW, Tang R, et al. Lateral flow assay based on paperhydrogel hybrid material for sensitive point-of-care detection of dengue virus. Adv Healthc Mater. Epub 2016 Nov 8.

35. Choi JR, Hu J, Feng S, Wan Abas WA, Pingguan-Murphy B, Xu F. Sensitive biomolecule detection in lateral flow assay with a portable temperature-humidity control device. Biosens Bioelectron. 2016;79:98-107.

36. Choi DH, Lee SK, Oh YK, et al. A dual gold nanoparticle conjugatebased lateral flow assay (LFA) method for the analysis of troponin I. Biosens Bioelectron. 2010;25(8):1999-2002.

37. He Y, Zhang S, Zhang X, et al. Ultrasensitive nucleic acid biosensor based on enzyme-gold nanoparticle dual label and lateral flow strip biosensor. Biosens Bioelectron. 2011;26(5):2018-2024.

38. Hu J, Wang S, Wang L, et al. Advances in paper-based point-of-care diagnostics. Biosens Bioelectron. 2014;54:585-597.

39. Cheung SF, Cheng SK, Kamei DT. Paper-based systems for point-ofcare biosensing. J Lab Autom. 2015;20(4):316-333.

40. Watanabe T, Ohkubo Y, Matsuoka H, et al. Development of a simple whole blood panel test for detection of human heart-type fatty acidbinding protein. Clin Biochem. 2001;34(4):257-263.

41. Mao X, Ma Y, Zhang A, Zhang L, Zeng L, Liu G. Disposable nucleic acid biosensors based on gold nanoparticle probes and lateral flow strip. Anal Chem. 2009;81(4):1660-1668.

42. Liu J, Lu Y. Preparation of aptamer-linked gold nanoparticle purple aggregates for colorimetric sensing of analytes. Nat Protoc. 2006; 1(1):246-252.

43. Breitner EK, Hussain SM, Comfort KK. The role of biological fluid and dynamic flow in the behavior and cellular interactions of gold nanoparticles. J Nanobiotechnology. 2015;13(1):1.

44. Black S, Kushner I, Samols D. C-reactive protein. J Biol Chem. 2004; 279(47):48487-48490.

45. De Lemos JA, Antman EM, Giugliano RP, et al. Very early risk stratification after thrombolytic therapy with a bedside myoglobin assay and the 12-lead electrocardiogram. Am Heart J. 2000;140(3):373-378.

46. Adams JE, Bodor GS, Dávilaromán VG, et al. Cardiac troponin I: A marker with high specificity for cardiac injury. Circulation. 1993; $88(1): 101$.

47. Weber M, Hamm C. Role of B-type natriuretic peptide (BNP) and NT-proBNP in clinical routine. Heart. 2006;92(6):843-849.

48. Gupta S, Huda S, Kilpatrick PK, Velev OD. Characterization and optimization of gold nanoparticle-based silver-enhanced immunoassays. Anal Chem. 2007;79(10):3810-3820.
49. Henderson K, Stewart J. Factors influencing the measurement of oestrone sulphate by dipstick particle capture immunoassay. J Immunol Methods. 2002;270(1):77-84.

50. Posthuma-Trumpie GA, Korf J, van Amerongen A. Lateral flow (immuno) assay: its strengths, weaknesses, opportunities and threats. A literature survey. Anal Bioanal Chem. 2009;393(2):569-582.

51. Chan CP, Sum KW, Cheung KY, et al. Development of a quantitative lateral-flow assay for rapid detection of fatty acid-binding protein. J Immunol Methods. 2003;279(1):91-100.

52. Sajid M, Kawde A-N, Daud M. Designs, formats and applications of lateral flow assay: a literature review. J Saudi Chem Soc. 2015;19(6): 689-705.

53. Leslie SB, Israeli E, Lighthart B, Crowe JH, Crowe LM. Trehalose and sucrose protect both membranes and proteins in intact bacteria during drying. Appl Environ Microbiol. 1995;61(10):3592-3597.

54. Chen Z-P, Peng Z-F, Zhang P, et al. A sensitive immunosensor using colloidal gold as electrochemical label. Talanta. 2007;72(5):1800-1804.

55. Aveyard J, Mehrabi M, Cossins A, Braven H, Wilson R. One step visual detection of PCR products with gold nanoparticles and a nucleic acid lateral flow (NALF) device. Chem Commun. 2007;41:4251-4253.

56. Laitinen MP, Vuento M. Affinity immunosensor for milk progesterone: identification of critical parameters. Biosens Bioelectron. 1996; 11(12):1207-1214

57. Fang C, Wu S, Duan N, Dai S, Wang Z. Highly sensitive aptasensor for oxytetracycline based on upconversion and magnetic nanoparticles. Anal Methods. 2015;7(6):2585-2593.

58. Mishra RK, Hayat A, Catanante G, Ocaña C, Marty JL. A label free aptasensor for Ochratoxin A detection in cocoa beans: an application to chocolate industries. Anal Chim Acta. 2015;889:106.

59. Mair J, Hammerer-Lercher A, Puschendorf B. The impact of cardiac natriuretic peptide determination on the diagnosis and management of heart failure. Clin Chem Lab Med. 2001;39(7):571-588.

60. Clerico A, Emdin M. Diagnostic accuracy and prognostic relevance of the measurement of cardiac natriuretic peptides: a review. Clin Chem. 2004;50(1):33-50.

61. Clerico A, Del Ry S, Giannessi D. Measurement of cardiac natriuretic hormones (atrial natriuretic peptide, brain natriuretic peptide, and related peptides) in clinical practice: the need for a new generation of immunoassay methods. Clin Chem. 2000;46(10):1529-1534. 


\section{Supplementary materials}

A

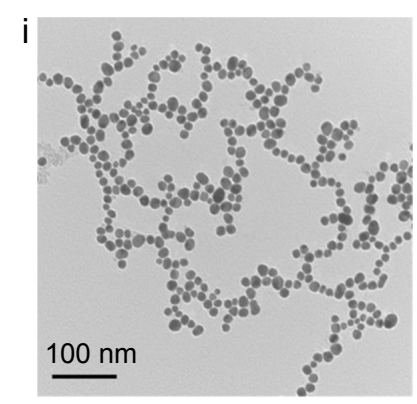

B

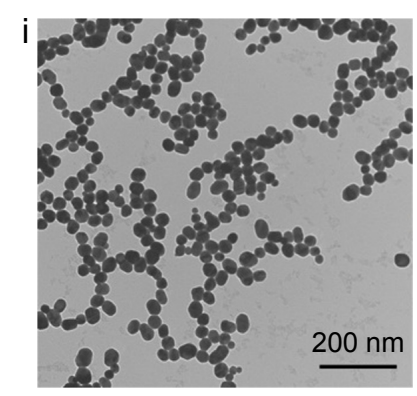

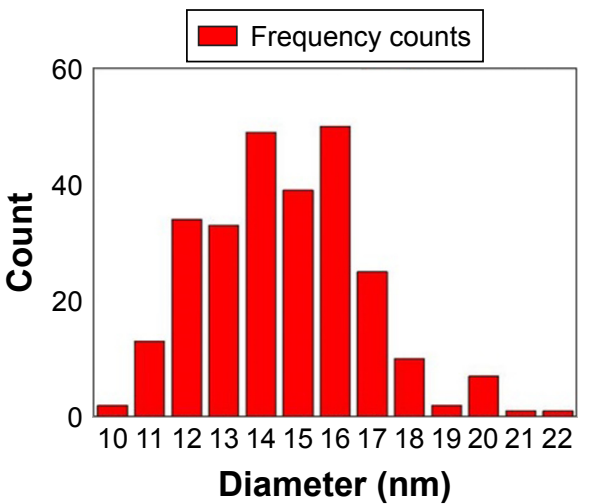

Diameter (nm)

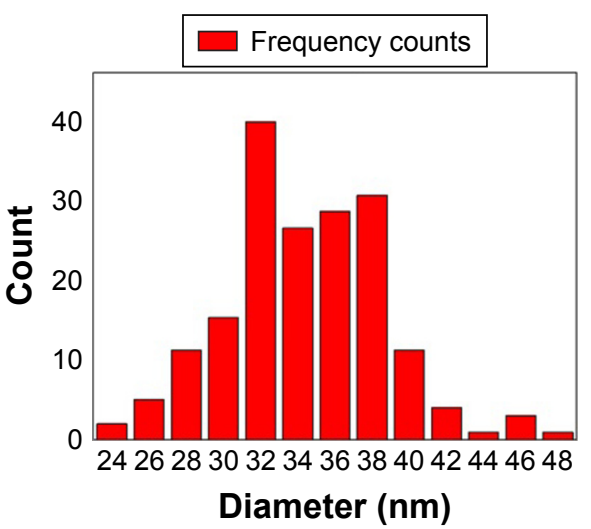

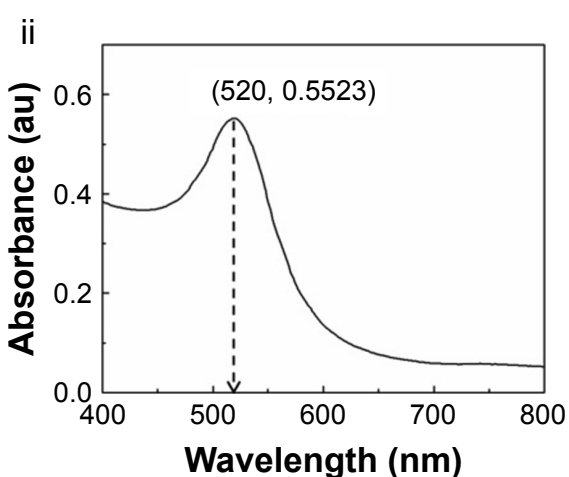

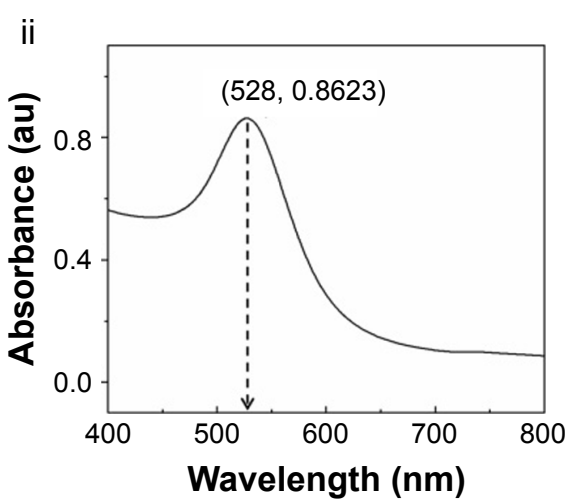

Figure SI Characterization of GNP.

Notes: (A) Characterization of GNP with $13 \mathrm{~nm}$ : (i) TEM and size distribution of GNP; (ii) UV-vis absorption spectra of GNP. (B) Characterization of GNP with 35 nm: (i) TEM and size distribution of GNP; (ii) UV-vis absorption spectra of GNP.

Abbreviations: GNP, gold nanoparticle; TEM, transmission electron microscopy; UV-vis, ultraviolet-visible.
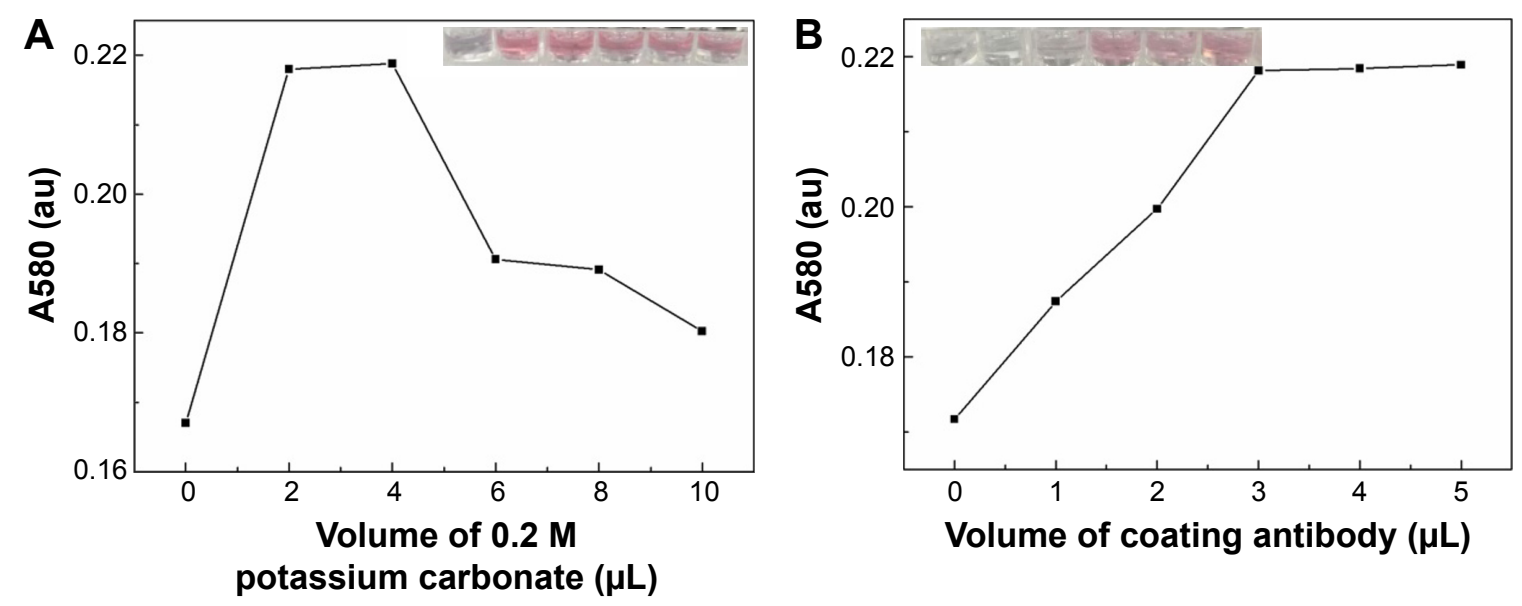

Figure S2 Determination of optimal $\mathrm{pH}$ and volume of conjugation.

Notes: (A) Determination of optimal pH for the conjugation of antibody to GNP (The inset shows the images of color change of pH optimization). (B) Determination of optimal volume of coating antibody for conjugation at $\mathrm{pH} 8$ (The inset shows the images of color change of volume optimization).

Abbreviation: GNP, gold nanoparticle. 


\section{Publish your work in this journal}

The International Journal of Nanomedicine is an international, peerreviewed journal focusing on the application of nanotechnology in diagnostics, therapeutics, and drug delivery systems throughout the biomedical field. This journal is indexed on PubMed Central, MedLine, CAS, SciSearch $\AA$, Current Contents $\AA /$ Clinical Medicine,

Journal Citation Reports/Science Edition, EMBase, Scopus and the Elsevier Bibliographic databases. The manuscript management system is completely online and includes a very quick and fair peer-review system, which is all easy to use. Visit http://www.dovepress.com/ testimonials.php to read real quotes from published authors.

Submit your manuscript here: http://www.dovepress.com/international-journal-of-nanomedicine-journal 